\title{
Living on the edge: a longitudinal study of Anopheles funestus in an isolated area of Mozambique
}

\author{
J Derek Charlwood ${ }^{1,2,3}$, Nelson Cuamba ${ }^{2}$, Elsa VE Tomás ${ }^{3}$ and Olivier JT Briët ${ }^{4,5^{*}}$
}

\begin{abstract}
Background: Understanding the survival strategies of malaria vectors at the edges of their distribution, where they are under stress from environmental conditions, may lead to the development of novel control techniques and may help predict the effects of climate change on these mosquitoes.

Methods: The population dynamics of an isolated population of Anopheles funestus from the peninsula of Linga Linga in southern Mozambique was studied over a period of 104 weeks from March 2009 to May 2011 by 917 light-trap and 390 exit collections, mostly in an area close to a seasonal pond.

Results: Over the sampling period, 3,684 An. funestus females were caught. Densities decreased with increasing distance from the pond. In 2009 and 2010, a single annual peak in An. funestus density coincident with the single annual peak in rainfall was observed, but a clear population peak was absent during the first 21 weeks of 2011. In between population peaks, An. funestus remained present at low densities. In light trap collections, the proportion of gravid mosquitoes was significantly higher during the 'low season' (the period between peaks) than during the peak season ( $R R=4.3, p<0.001$ ). In contrast, in exit collections, the proportion of gravid mosquitoes was significantly lower during low season than during the peak season ( $R R=0.64, p<0.01)$. Also, in light traps, the proportion of part-fed females was higher during the low season than during the peak season $(R R=4.5, p<0.001)$, whereas this was inversed for engorged females ( $R R=0.46, p<0.05)$.

Thirteen out of 289 (4.5\%) An. funestus tested positive in the sporozoite ELISA. The proportion of sporozoite positive females was higher during the low season (6.25\%, six out of 96$)$ than during the peaks (3.63\%, seven out of 193), but this difference was not significant.
\end{abstract}

Conclusions: It is suggested that a proportion of the mosquito population may become gonotrophically discordant during the long dry season resulting in enhanced mosquito survival and sustained malaria transmission.

Keywords: Anopheles funestus, Aestivation, Survival, Island

\section{Background}

The dynamics of malaria vectors are particularly interesting at the edges of their distribution since it is there that they are furthest from the centre of their niche and it is there that they are likely to be under stress from environmental conditions. At the edges of their distribution, species are likely to form meta populations, that is, small isolated populations each of which may temporarily become extinct, the

\footnotetext{
* Correspondence: olivier.briet@unibas.ch

${ }^{4}$ Swiss Tropical and Public Health Institute, Socinstrasse 57, PO Box, CH-4002, Basel, Switzerland

${ }^{5}$ University of Basel, PO Box, CH-4003, Basel, Switzerland

Full list of author information is available at the end of the article
}

habitat remaining empty until recolonized. By focusing on the ecology of mosquitoes in extreme conditions, the reasons for extinction might be determined which could inform strategies to eliminate the mosquito over wider areas. Understanding the survival strategies of mosquitoes in these situations may also help predict the effects of climate change on these vectors and may also lead to the development of novel control techniques. Rather than using a blanket approach, targeted approaches that enhance the effects of natural stresses may be useful.

One way for mosquitoes to cope with stresses of temporarily unsuitable conditions is to aestivate (during hot and

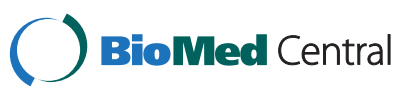


dry periods) or hibernate (during cold periods). In doing so, they become gonotrophically discordant and take multiple blood meals per egg batch. To paraphrase Tolstoy [1], all gonotrophically concordant populations of anophelines are the same, whereas all gonotrophically discordant populations are discordant in their own way. The term 'gonotrophically discordant' was first introduced by Roubaud [2] to describe multiple blood-feeding in hibernating Anopheles atroparvus from northern Europe. Hibernation occurs in temperate zones, induced by short day lengths. In hibernating populations, all mosquitoes are affected, and gonotrophic discordance is complete. Aestivation, which has been discussed in detail by Washino [3], occurs in torrid zones (tropics). Not all mosquitoes in such populations aestivate, and gonotrophic discordance is not complete. Gonotrophic discordance of this sort has been described among Anopheles maculatus, Anopheles culicifacies, Anopheles annularis and Anopheles aconitus from India and Southeast Asia [4-6].

In Africa, studies on gonotrophic discordance have largely been limited to members of the Anopheles gambiae complex. At the extreme north of their distribution in the Sudan, Anopheles arabiensis can aestivate: during the long dry season, adult females rest inside houses or turkels and are prone to take small blood meals for survival purposes without developing more than a single egg batch [7]. Thus, they enter the dry season as young unfed females and end it as gravid ones. Because they take multiple blood meals per egg batch, even low numbers of such mosquitoes pose a threat since they survive for much longer than the extrinsic cycle of the parasite, hence infection rates may be high. However, in the presence of adequate breeding sites, such as the spill from water tanks in refugee camps, the mosquitoes continue to breed normally $[8,9]$. Consequently, for normal breeding, the availability of water is a critical component of their dynamics.

Holstein [10] considered that the An. gambiae s.l. found resting in the dry season in Upper Volta existed in a state midway between gonotrophic discordance (or disassociation) and gonotrophic concordance, developing eggs but blood-feeding whenever the opportunity arose. In the Sudan, three-quarters of the gonotrophically discordant An. arabiensis sampled by Omer and Cloudsley-Thompson [7], all of which were nulliparous, contained blood. More recently, Lehmann and colleagues have described a similar aestivation phenomenon occurring in Anopheles coluzzi (previously known as the $\mathrm{M}$ form of An. gambiae [11]), with one marked specimen being collected seven months after initial release $[12,13]$. They considered that the rise in density five days after the first rain was due to aestivating mosquitoes emerging from their resting sites. Neither the sympatric An. gambiae (previously known as the $\mathrm{S}$ form of $A n$. gambiae), nor Anopheles funestus, nor, surprisingly, $A n$. arabiensis, aestivated in this way. Such an explanation for the rapid re-appearance of mosquitoes is also mentioned by Muir [14]. Gillies [15,16] observed a similar phenomenon in An. gambiae in Muheza, Tanzania, but did not ascribe it to any cause. Should it have been due to aestivating insects, then this would imply that the behaviour is possible in all freshwater members of the $A n$. gambiae complex, but that each species does or does not aestivate according to local conditions. Thus, aestivation was not observed in vectors in the semi-arid Kilombero Valley in Tanzania. Here, during the rainy season, rain-fed rice fields provide suitable breeding sites, and at the start of the long dry season, the vectors appeared to retreat into separate refugia where they were locally common: An. gambiae occurred close to the forested escarpment of the Uduzungwa Mountains where rainfall was over $200 \mathrm{~mm} /$ annum and where artisanal irrigation was practiced, An. arabiensis occurred at the margins of the Kilombero River (where it bred in animal footprints), and An. funestus was found in places where seasonal rivers had remained as substantial shaded ponds, without evidence of any form of gonotrophic disassociation [17] This makes it difficult to generalize the life-history strategies adopted by different species in different areas. In each of the situations where aestivation has been reported, however, one of the factors that characterized the mosquitoes was an exceptionally long survival time.

The one instance of gonotrophic discordance recorded in An. funestus was in hibernating rather than in aestivating mosquitoes: Leeson in 1931 ([18] quoted in [19]) found gravid females overwintering in cracks in rocks and riverbanks in Zimbabwe. Once temperatures rose, they left these sites, oviposited and died. Little is known about the biology of An. funestus in hot and dry environments and the threat that it poses there in terms of malaria transmission. Such environments may increase as a result of global warming with the associated reduction in rainfall in southern Africa [20]. One such hot and dry environment where continuous breeding is not possible, but where malaria is endemic and perennial, is the Linga Linga peninsula in southern Mozambique.

Here, two years of sampling are described and it is suggested that, in the absence of rain, An. funestus in Linga Linga is present for long periods, largely as low-density, gonotrophically discordant, females, which are effective vectors of malaria.

\section{Methods}

\section{Description of the study site}

Bordered on one side by the Indian Ocean and on the other by Morrumbene Bay, the approximately 2 by $7 \mathrm{~km}$ peninsula of Linga Linga $\left(23.7^{\circ} \mathrm{S}, 35.4^{\circ} \mathrm{E}\right)$ (Figure 1) is a sandy finger of land in southern Mozambique, opposite 


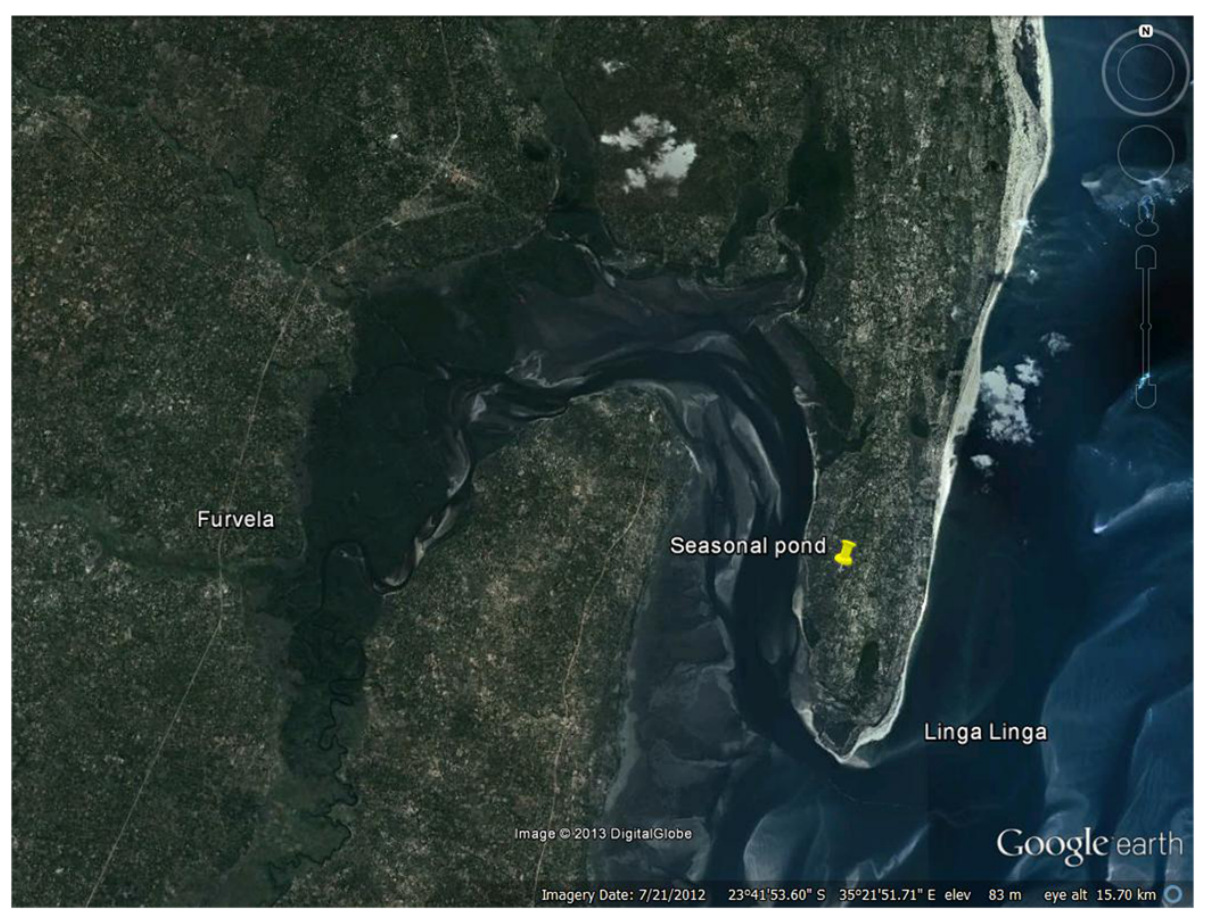

Figure 1 Location of Linga Linga relative to Furvela.

the capital of Inhambane Province and $8 \mathrm{~km}$ by boat from the district capital, the town of Morrumbene, which can also be reached by a $23-\mathrm{km}$ sand road. There is an area of uninhabited bush, circa $1.5 \mathrm{~km}$ long, at the neck of the peninsula making it a virtual ecological 'island'. Fruit trees, notably cashew and marula, are grown in addition to large numbers of coconut palms. Some manioc and beans are cultivated in a limited area of the peninsula. A malaria control project was initiated in 2007. At the start of the project, all houses in the peninsula were mapped with handheld GPS units (Garmin e-Trex). Houses were numbered, photographed and their dimensions noted. Residents were informed of the purpose of the project and consented to participate.

Four hundred of the 467 houses enumerated in 2007 consisted of just a single room, 48 had two rooms and only 19 had more than two rooms. Most (87\%) were built of either palm or reed and most had a gap between the roof and the walls, thus providing access for mosquitoes. Three-quarters of the houses had only one or two inhabitants. Half the households had a radio and $16 \%$ owned a mobile phone.

In a baseline malaria prevalence survey conducted in 2007, when no interventions were in use and there was no clinic on the peninsula, prevalence peaked at 35\% in two to four-year olds, significantly lower than the $80 \%$ observed in the village of Furvela, across the bay. In addition to the 984 people enumerated in the initial census, the peninsula supported a population of circa 300 goats, 200 pigs and 26 dogs. Most people also kept chickens. Apart from a seasonal pond close to the middle of the peninsula and a permanent lake at its northern end, naturally occurring standing water is almost non-existent in Linga Linga. The water table is relatively high, however, and in the dry season, people dig shallow wells to obtain water for their crops.

\section{Entomology}

Two methods of collection for adult mosquitoes were used. Light-traps hung inside an occupied bedroom in which the occupant slept under a bed net were used for the collection of host-seeking females from 28 March 2009 (ISO week 13) to 24 May 2011 (ISO week 21). Exit collections, as described by Charlwood [21], were used to sample mosquitoes leaving houses at dusk from 25 May 2009 (ISO week 22) to 23 May 2011 (ISO week 21). Initial collections were undertaken in two areas of the peninsula and were subsequently concentrated in a group of houses close to the seasonal pond (Figure 2), a known breeding site. Thus, light-trap collections (from 16 April 2009 onwards) and exit collections (from 4 August 2009 onwards) were concentrated in an area expected to be one with a high density of vectors. Collected mosquitoes were categorized according to genus and as male or female. Females were further categorized according to abdominal status (unfed, part fed, semigravid or gravid). Anophelines were identified morphologically according to the keys of Gillies and De Meillon [19] and Gillies and Coetzee [22]. 


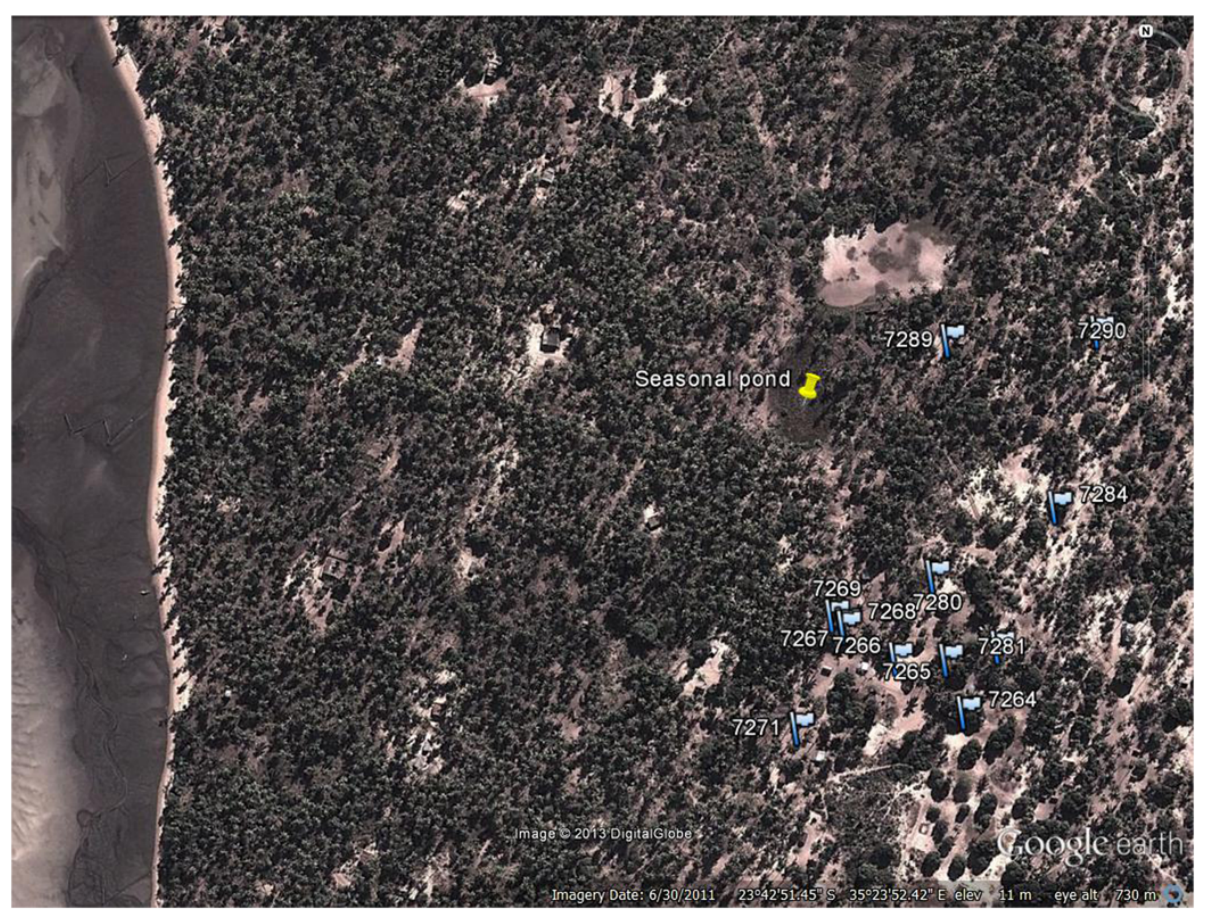

Figure 2 Location of sampled houses in Linga Linga near the seasonal pond. Numbers correspond to house identifiers listed in Table 2.

A subsample of the An. funestus collected during 2009 and stored over silica gel was tested for the presence of circumsporozoite protein in an enzyme linked immunosorbent assay (ELISA) using the protocols of Wirtz [23].

\section{Meteorology}

For the entire study period, daily rainfall data from the town of Maxixe, approximately $15 \mathrm{~km}$ from Linga Linga, kindly provided by the Rio-Sul water management project, were used to compare mosquito numbers with environmental conditions. Also, for the year 2010, rainfall data were available from a digital weather station [24] which was established close to the southern tip of the peninsula with 360-degree exposure to wind.

\section{Table 1 Comparison of collection results between the} southern end and the middle of the peninsula

\begin{tabular}{|c|c|c|c|c|}
\hline \multirow{2}{*}{$\begin{array}{l}\text { Collection method } \\
\text { Zone }\end{array}$} & \multicolumn{2}{|c|}{$\begin{array}{l}\text { Exit (25 May to } 3 \\
\text { August 2009) }\end{array}$} & \multicolumn{2}{|c|}{$\begin{array}{l}\text { Light traps (28 March to } \\
15 \text { April 2009) }\end{array}$} \\
\hline & Tip & Middle & Tip & Middle \\
\hline$n$ & 56 & 47 & 12 & 5 \\
\hline An. funestus females & 0.07 & 5.40 & 0.08 & 0.00 \\
\hline An. funestus males & 0.02 & 6.57 & 0.00 & 0.00 \\
\hline Culex spp. females & 5.09 & 1.87 & 18.17 & 29.60 \\
\hline Culex spp. males & 1.04 & 3.43 & 0.42 & 0.00 \\
\hline
\end{tabular}

Numbers indicate density per collection. The number of collections is indicated by $\mathrm{n}$.

\section{Statistical methods}

Data was analysed in the statistical environment $R$ [25]. Fisher's exact test was used to calculate significance for rate ratios of abdominal states between seasons. The relationship between the mosquito density in houses and house characteristics (distance from pond and the number of inhabitants) was analysed using negative binomial regression with the number of mosquitoes collected as outcome variable, a logarithmic link function and the logarithmically transformed number of samples as offset [26].

\section{Ethical clearance}

The project received ethical clearance from the National Bioethics Committee of Mozambique on 2August 2006 (reference 123/CNBS/06).

\section{Results}

All mosquitoes classified as a member of the An. funestus group examined in detail had a single pale spot on the upper branch of the fifth vein and no pale spot at the tip of the sixth vein. In other words, they were morphologically all An. funestus. It appears reasonable to presume that it was the only member of the group being collected. Between 28 March 2009 and 24 May 2011, 3,684 An. funestus females and 91 males, 2,028 Culex quinquefasciatus females and 124 males, 67 Mansonia spp. and 106 unidentified culicines were collected during 961 light-trap nights and 790 female and 1,362 male An. funestus and 1,174 female and 
Table 2 Collection results for the $\mathbf{1 2}$ most sampled houses

\begin{tabular}{|c|c|c|c|c|c|c|c|c|c|c|c|c|}
\hline \multirow[t]{3}{*}{ House } & \multirow[t]{3}{*}{ Inhabitants } & \multirow{3}{*}{$\begin{array}{l}\text { Distance } \\
\text { from pond } \\
(\mathrm{m})\end{array}$} & \multicolumn{5}{|c|}{ Light-trap collections } & \multicolumn{5}{|c|}{ Exit collections } \\
\hline & & & \multirow[b]{2}{*}{ n } & \multicolumn{2}{|c|}{ An. funestus } & \multicolumn{2}{|c|}{ Culex spp. } & \multirow[b]{2}{*}{$\mathbf{n}$} & \multicolumn{2}{|c|}{ An. funestus } & \multicolumn{2}{|c|}{ Culex spp. } \\
\hline & & & & Females & Males & Females & Males & & Females & Males & Females & Males \\
\hline 7264 & 4 & 222 & 105 & 403 & 4 & 178 & 14 & 33 & 50 & 92 & 87 & 107 \\
\hline 7280 & 1 & 134 & 97 & 201 & 36 & 124 & 8 & 25 & 48 & 42 & 55 & 63 \\
\hline 7281 & 2 & 195 & 92 & 331 & 16 & 125 & 17 & 27 & 107 & 153 & 70 & 89 \\
\hline 7267 & 4 & 135 & 82 & 654 & 1 & 241 & 15 & 47 & 125 & 164 & 143 & 163 \\
\hline 7265 & 1 & 166 & 78 & 105 & 0 & 92 & 6 & 13 & 17 & 12 & 27 & 29 \\
\hline 7289 & 3 & 96 & 73 & 97 & 1 & 130 & 6 & 14 & 14 & 64 & 36 & 62 \\
\hline 7271 & 1 & 210 & 67 & 47 & 0 & 129 & 4 & 27 & 35 & 40 & 66 & 92 \\
\hline 7266 & 2 & 183 & 63 & 214 & 6 & 44 & 1 & 12 & 58 & 123 & 44 & 40 \\
\hline 7269 & 2 & 129 & 48 & 1215 & 4 & 92 & 14 & 24 & 120 & 337 & 55 & 38 \\
\hline 7284 & 1 & 172 & 46 & 60 & 0 & 45 & 2 & 11 & 28 & 10 & 26 & 31 \\
\hline 7268 & 1 & 139 & 26 & 48 & 4 & 34 & 6 & 14 & 54 & 208 & 20 & 31 \\
\hline 7290 & 1 & 200 & 18 & 8 & 0 & 31 & 1 & 2 & 1 & 2 & 2 & 3 \\
\hline
\end{tabular}

The number of collections is indicated by $n$.

1,026 male Cx. quinquefasciatus, 20 Mansonia spp. females and 22 unidentified culicines were caught during 391 exit collections undertaken in 59 houses, four of which were sampled more than 120 times. A comparison of mosquito densities in exit collections done during the period 25 May to 3 August 2009 showed that close to the tip of the peninsula, very few $A n$. funestus were present as compared to in the middle of the peninsula (Table 1). The situation was inversed for Culex spp. A comparison of light-trap collections (over a much shorter period) was inconclusive. Subsequent analysis excludes data from houses near the tip of the peninsula.

Figure 2 shows the location of the houses most commonly sampled relative to the seasonal pond and coast. Table 2 shows their collection results, including distance from the pond, and number of regular inhabitants. Table 3 shows results from negative binomial regression. In light-trap collections, An. funestus female density significantly decreased with distance from the pond, and increased with the number of inhabitants. The density of An. funestus males also decreased significantly with distance, but decreased with the number of inhabitants. Culex spp. density increased with inhabitants both in light-trap and exit collections, but was unrelated to distance from the pond.
Figure 3 shows the weekly density of An. funestus collected using light traps (panel a), those exiting at dusk (panel c) on square root scales, and rainfall from Linga Linga (panel e) and Maxixe (panel f). In 2009 and 2010, a single annual peak in density coincident with the single annual peak in rainfall was observed. Curiously, a clear population peak was absent during the first 21 weeks of 2011. During the first half of 2010, rainfall measurements in Linga Linga showed a high correlation with those from Maxixe, but showed little rainfall towards the end of 2010 (see also Figure 4 for more detail), whereas rainfall was more substantial in Maxixe during that period. Light traps predominantly caught females, whereas many males were also caught while exiting houses at dusk. In between population peaks, $A n$. funestus remained present at low densities. Figure 3 also shows weekly data on the unfed proportion of the female $A n$. funestus collected in light-traps (panel b) and exiting houses at dusk (panel d). Despite the noisy nature of these data, the proportion of unfed females appears to increase with increasing density. Temperature and relative humidity stayed high throughout the year (Figure 4).

Table 4 shows the detailed information about the abdominal status of female An. funestus by season and by collection method. Peak season was defined as weekly

Table 3 Regression coefficients of mosquito density depending on house characteristics

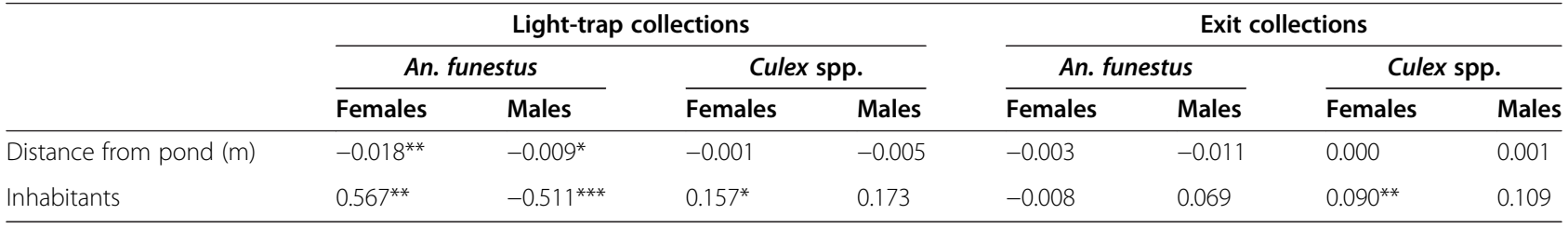

a: ${ }^{* *} 0.001,{ }^{* *} 0.01,{ }^{*} 0.05$. 

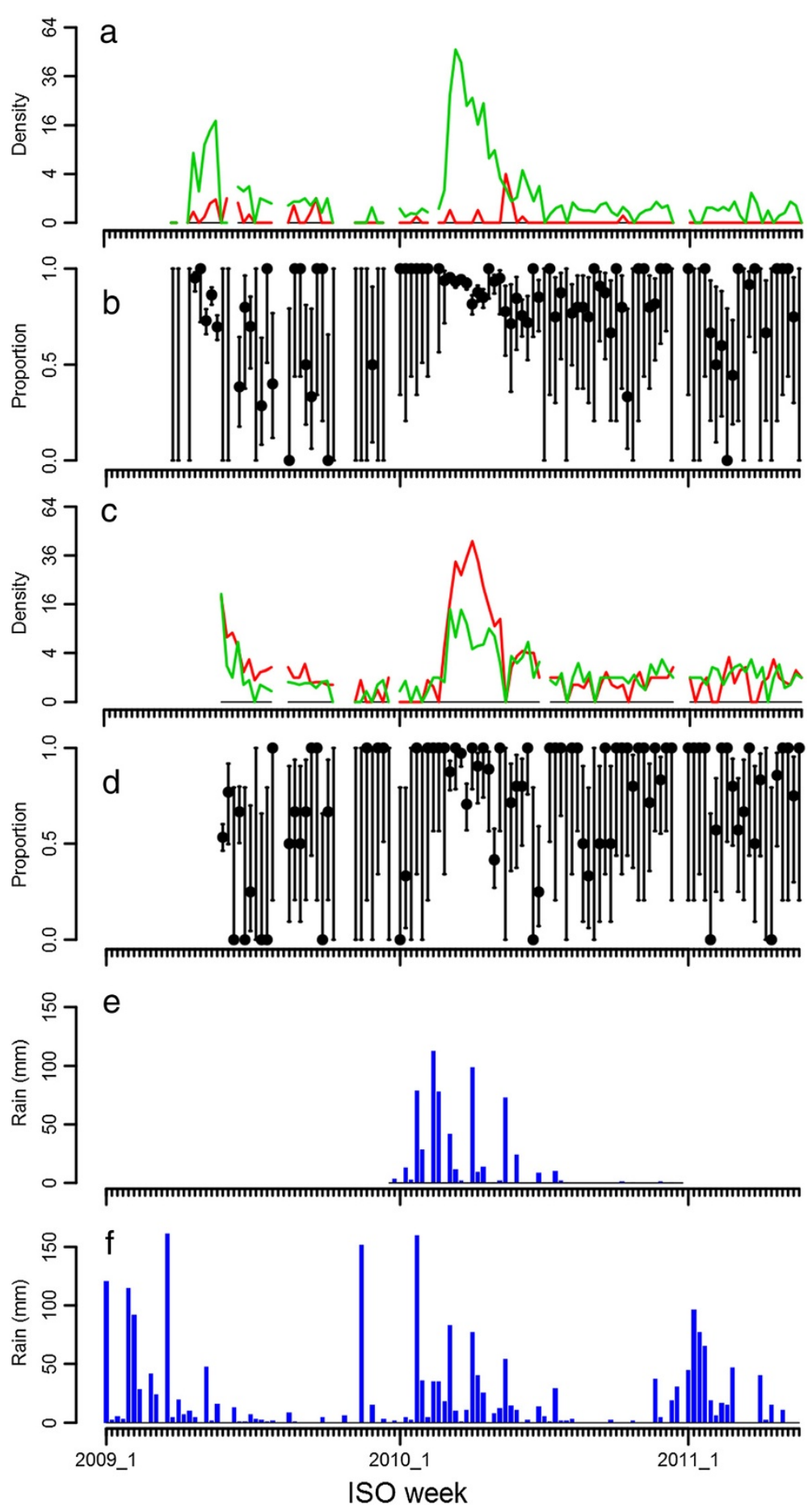

Figure 3 Anopheles funestus density, and proportion gravid and rainfall over the study period. a) An. funestus density in light trap collections. The green line corresponds to females and the red line corresponds to males. b) Proportion of unfed An. funestus females in light trap collections. Black dots indicate the mean and bars indicate the $95 \%$ confidence interval. c) An. funestus density in exit collections. The green line corresponds to females and the red line corresponds to males. d) Proportion of unfed An. funestus females in exit collections. Black dots indicate the mean and bars indicate the $95 \%$ confidence interval. e) Weekly rainfall in $\mathrm{mm}$ measured in Linga Linga. f) Weekly rainfall in mm measured in Maxixe. 

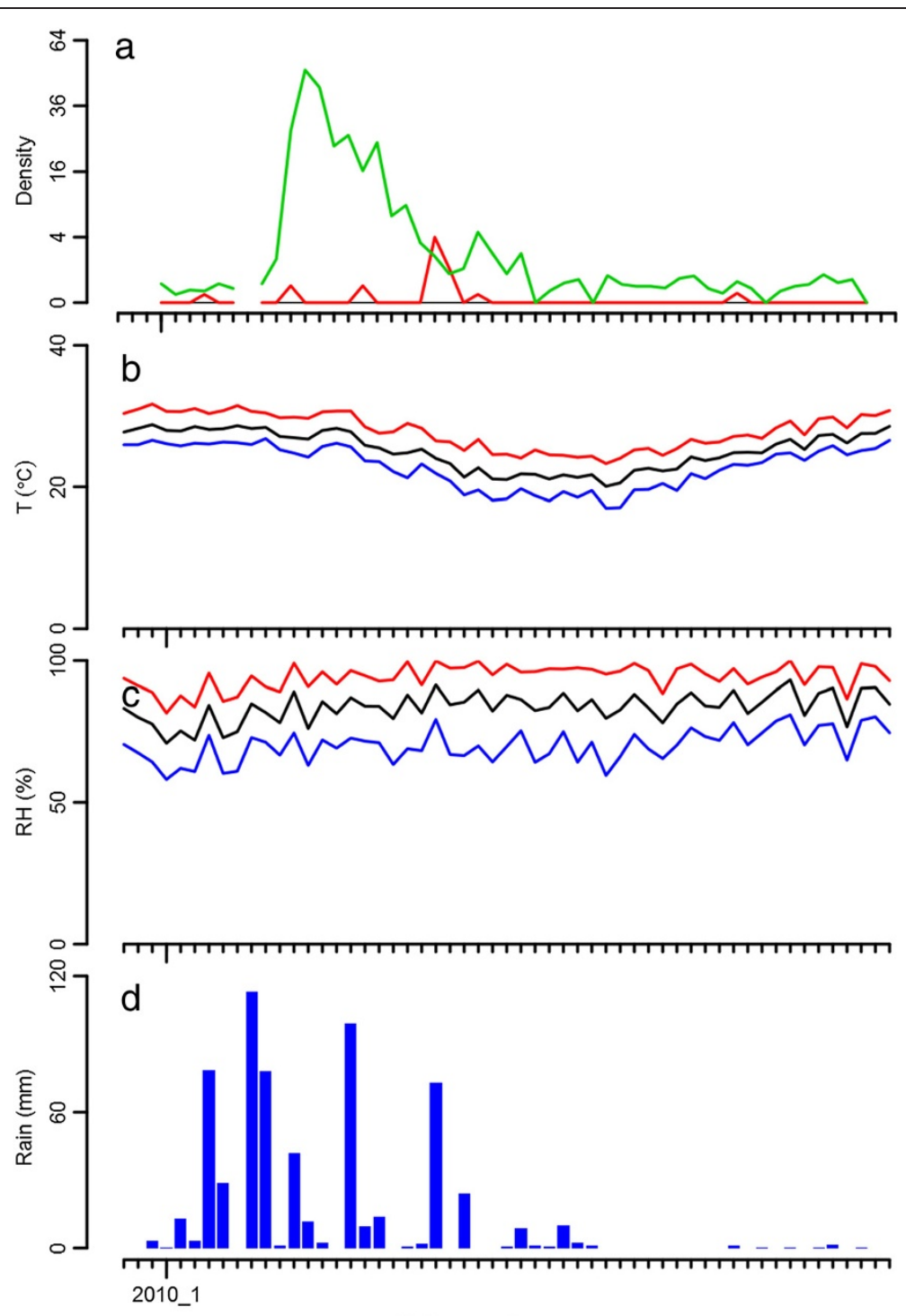

\section{ISO week}

Figure 4 Anopheles funestus density in Linga Linga and weather by ISO week over 2010. a) An. funestus density in light trap collections. The green line corresponds to females and the red line corresponds to males. b) Temperature ( $T$ ) in degrees Celsius averaged by week. The red line corresponds to the daily maximum, the black to the daily mean, and the blue to the daily minimum. c) Per cent relative humidity (RH) averaged by week. The red line corresponds to the daily maximum, the black to the daily mean, and the blue to the daily minimum. d) Weekly rainfall in $\mathrm{mm}$.

density or three week moving average densities of over five females per sample, which corresponds to periods of ISO weeks 17 to 22 in 2009 and ISO weeks 9 to 18 in 2010. In light-trap collections, the proportion of gravid mosquitoes was significantly higher during low season than during the peak season $(R R=4.3, p<0.001)$. In contrast, in exit collections, the proportion of gravid mosquitoes was significantly lower during low season than during the peak season $(R R=0.64, p<0.01)$. Also, in light traps, the proportion of part-fed females was higher during the low season than during the peak season $(R R=$
4.5, $p<0.001)$, whereas this was inversed for engorged females $(R R=0.46, p<0.05)$.

Overall, female An. funestus were significantly more often part-fed $(R R=2.1, \mathrm{p}<0.001)$ and semigravid $(R R=$ $2.2, \mathrm{p}<0.001)$ in exit collections than in light-trap collections (Table 5).

Thirteen out of 289 (4.5\%) An. funestus tested positive in the sporozoite ELISA, five being high density infections and eight being low density ones. The proportion of sporozoite-positive females was higher during the low season $(6.25 \%$, six out of 96$)$ than during the peaks 
Table 4 Comparison of the distribution of Anopheles funestus abdominal state between seasons depending on collection type

\begin{tabular}{|c|c|c|c|c|c|c|c|c|c|c|c|c|}
\hline \multirow{3}{*}{$\begin{array}{l}\text { Type } \\
\text { Season }\end{array}$} & \multicolumn{6}{|c|}{ Exit collection } & \multicolumn{6}{|c|}{ Light-trap collection } \\
\hline & \multicolumn{2}{|c|}{ Low } & \multicolumn{2}{|c|}{ Peak } & \multirow{2}{*}{$\begin{array}{l}\text { Season } \\
\text { RR }\end{array}$} & \multirow{2}{*}{$\begin{array}{l}\text { Low } \\
\text { Sign }\end{array}$} & \multicolumn{2}{|c|}{ Peak } & \multicolumn{2}{|c|}{ Season } & \multirow{2}{*}{$\begin{array}{l}\text { Low } \\
\text { RR }\end{array}$} & \multirow{2}{*}{$\begin{array}{l}\text { Peak } \\
\text { Sign. }\end{array}$} \\
\hline & $\%$ & n & $\%$ & $\mathbf{n}$ & & & $\%$ & $\mathbf{n}$ & $\%$ & $\mathbf{n}$ & & \\
\hline Collections & & 85 & & 11 & & & & 86 & & 16 & & \\
\hline Unfed & 75.5 & 219 & 71.6 & 355 & 1.06 & NS & 77.8 & 351 & 89.0 & 2876 & 0.87 & $* * *$ \\
\hline Part fed & 8.3 & 24 & 5.4 & 27 & 1.52 & NS & 2.7 & 12 & 0.6 & 19 & 4.53 & $* * *$ \\
\hline Fed & 2.1 & 6 & 1.8 & 9 & 1.14 & NS & 1.6 & 7 & 3.3 & 108 & 0.46 & * \\
\hline Semigravid & 0.7 & 2 & 0.2 & 1 & 3.42 & NS & 3.1 & 14 & 3.6 & 117 & 0.86 & NS \\
\hline Gravid & 13.4 & 39 & 21.0 & 104 & 0.64 & $* *$ & 14.9 & 67 & 3.5 & 112 & 4.29 & $* * *$ \\
\hline Total & 100.0 & 290 & 100.0 & 496 & & & 100.0 & 451 & 100.0 & 3232 & & \\
\hline Part fed + fed & 10.3 & 30.0 & 7.3 & 36.0 & 1.43 & NS & 4.2 & 19.0 & 3.9 & 127.0 & 1.07 & NS \\
\hline Semi-gravid + gravid & 14.1 & 41.0 & 21.2 & 105.0 & 0.67 & * & 18.0 & 81.0 & 7.1 & 229.0 & 2.53 & $* * *$ \\
\hline
\end{tabular}

n: count; RR: rate ratio; Sign.: significance in Fisher's exact test; $a:{ }^{* * *} 0.001,{ }^{* *} 0.01,{ }^{*} 0.05$, NS 1 .

(3.63\%, seven out of 193), but this difference was not significant (Fisher's exact test, $\alpha=0.05$ ).

\section{Discussion}

Although the An. funestus were not identified to species by polymerase chain reaction, given that all specimens examined in detail morphologically keyed out to this member of the group, its endophilic behaviour and the sporozoite rate observed, it seems reasonable to assume that most, if not all, mosquitoes identified in Linga Linga were An. funestus. Two population density peaks were observed over a 104-week period of collection, both occurring within the first 21 weeks of the year, during and following the rainy season. With relative humidity and temperature being favourable throughout the year, rather than being driven by temperature (as occurs in a number of other An. funestus populations [19]) rainfall apparently determines the population dynamics on Linga Linga. However, during the first 21 weeks of a third year, a clear population density peak was absent. Despite some apparent association of adult density in houses with rainfall and with proximity to a seasonal pond (in which anopheline larvae were found), breeding in other places (such as the shallow wells dug during the dry season) cannot be excluded. Such breeding sites could be responsible for the low but continued presence of An. funestus during the dry season. The fact that in Linga Linga, males continued to be present in exit collections during the dry season could also indicate continued breeding, but with some sources of nectar available, it is also possible that the males will

Table 5 Comparison of the distribution of Anopheles funestus abdominal state between collection types depending on season

\begin{tabular}{|c|c|c|c|c|c|c|c|c|c|c|c|c|c|c|}
\hline \multirow{3}{*}{$\begin{array}{l}\text { Season } \\
\text { Type }\end{array}$} & \multicolumn{6}{|c|}{ Low } & \multicolumn{6}{|c|}{ Peak } & \multirow[t]{2}{*}{ All } & \multirow[b]{2}{*}{ Type } \\
\hline & \multicolumn{2}{|c|}{ Exit collection } & \multicolumn{2}{|c|}{ Light-trap collection } & \multirow[b]{2}{*}{ RR } & \multirow[b]{2}{*}{ Sign. } & \multicolumn{2}{|c|}{ Type } & \multicolumn{2}{|c|}{ Exit collection } & \multirow{2}{*}{$\begin{array}{l}\text { Light-trap } \\
\text { collection } \\
\text { RR }\end{array}$} & \multirow[b]{2}{*}{ Sign. } & & \\
\hline & $\%$ & $n$ & $\%$ & $n$ & & & $\%$ & $\mathrm{n}$ & $\%$ & $\mathbf{n}$ & & & $\mathbf{R R}$ & Sign. \\
\hline Collections & & 85 & & 86 & & & & 11 & & 16 & & & & \\
\hline Unfed & 75.5 & 219 & 77.8 & 351 & 0.97 & NS & 71.6 & 355 & 89.0 & 2876 & 0.80 & $* * *$ & 0.83 & $* * *$ \\
\hline Part fed & 8.3 & 24 & 2.7 & 12 & 3.11 & $* * *$ & 5.4 & 27 & 0.6 & 19 & 9.26 & $* * *$ & 7.71 & $* * *$ \\
\hline Fed & 2.1 & 6 & 1.6 & 7 & 1.33 & NS & 1.8 & 9 & 3.3 & 108 & 0.54 & NS & 0.61 & NS \\
\hline Semigravid & 0.7 & 2 & 3.1 & 14 & 0.22 & $*$ & 0.2 & 1 & 3.6 & 117 & 0.06 & $* * *$ & 0.11 & $* * *$ \\
\hline Gravid & 13.4 & 39 & 14.9 & 67 & 0.91 & NS & 21.0 & 104 & 3.5 & 112 & 6.05 & $* * *$ & 3.74 & $* * *$ \\
\hline Total & 100.0 & 290 & 100.0 & 451 & & & 100.0 & 496 & 100.0 & 3232 & & & & \\
\hline Part fed + fed & 10.3 & 30.0 & 4.2 & 19.0 & 2.46 & $* * *$ & 7.3 & 36.0 & 3.9 & 127.0 & 1.85 & $* *$ & 2.12 & $* * *$ \\
\hline Semi-gravid + gravid & 14.1 & 41.0 & 18.0 & 81.0 & 0.79 & NS & 21.2 & 105.0 & 7.1 & 229.0 & 2.99 & $* * *$ & 2.21 & $* * *$ \\
\hline
\end{tabular}

n: count; RR: rate ratio; Sign.: significance in Fisher's exact test; a: ${ }^{* * *} 0.001,{ }^{* *} 0.01,{ }^{*} 0.05$, NS 1. 
survive as long as females. By contrast, in the Sahel, male mosquitoes disappear during the dry season, since none of the plants that might be a source of sugar blossom during that period [7]. Mosquito populations were not investigated close to the permanent lake at the northern end of the peninsula and it is possible that some immigration from this site occurred in the study area, migration of older mosquitoes from Furvela, $8 \mathrm{~km}$ across the bay, was also possible though unlikely due to the wide natural barrier of salt water. Otherwise, the village of Furvela is bordered on two sides by the floodplains of the Furvela and Ngombe rivers, both of which are perennial. Breeding continues throughout the year in Furvela and is not associated with rainfall.

The higher proportions of gravid and partially fed females in light traps during the low season compared to during the peak season, coupled with lower proportions of unfed females, indicate that during the low season, proportionally more gravid and partially fed females may be searching for a blood meal. This cannot easily be explained by the possibility of there simply being more gravid (and less virgin) females around during the low season, because in exit collections at dusk, the proportion of gravid females was lower during the low season than during the peak season. In the absence of interventions, such as bed nets, when most host-searching females manage to feed, exit collections at dusk were typically dominated by gravid mosquitoes in search of an oviposition site, and virgin mosquitoes in search of a mate (19). In Linga Linga, where bed nets were used, as in the sentinel houses, the proportion of host-searching females that failed to find a host the previous night may be somewhat larger (20). Nevertheless, even if there were proportionally more gravid mosquitoes during the low season (as indicated by the results from the light-trap collections), then these endophilic mosquitoes might not be exiting from houses to oviposit (due to a lack of breeding sites) but instead linger longer around or in houses, and presumably, when hungry, will still feed on people, hence the relatively low proportion of gravid females in exit collections.

\section{Conclusions}

During the rainy season, the An. funestus population in Linga Linga is a typically gonotrophically concordant one (with high densities of unfed females in light-trap collections and gravid ones in exit collections). However, the analysis suggests gonotrophic discordance as a possible explanation for the observed abdominal status distributions in collections during the dry season. Unfortunately, no dissections were done to establish mating status, and ovary status, which could support such an explanation. The observed sporozoite rate of $4.5 \%$, in the presence of a relatively low infection prevalence in humans who predominately use bed nets, also implies a high mosquito life expectancy. Despite the low numbers of mosquitoes collected, positive cases of malaria (determined by microscopy and/or rapid test) occurred throughout the year [Charlwood, unpublished observations]. Therefore, for periods when breeding sites are scarce, it is suggested that such malaria transmission in Linga Linga may be largely sustained by a small number of long-lived, gonotrophically discordant, females.

\section{Competing interests}

The authors declare that they have no competing interests.

\section{Authors' contributions}

JDC conceived of the study, and wrote the manuscript; NC helped with logistics and the study design; EVET helped with mosquito collection and performed the ELISA; OJTB performed statistical analysis, and wrote the manuscript. All authors read and approved the final manuscript.

\section{Acknowledgements}

This work would not have been possible without the dedication of Mr Lopes Joaquim who did much of the field work described in this paper. We would like to thank Vestergaard-Frandsen Company for their donation of the mosquito nets used in this study and for their interest throughout. JDC would like to thank the director of DBL, Niels Ørnberg, for his unstinting support throughout this and other work in Mozambique and the Bill and Melinda Gates Foundation (BMGF) for supplying funds to buy the weather station. OJTB was supported through the Malaria Modelling Project \#OPP1032350 funded by the BMGF.

\section{Author details}

'DBL Centre for Health, Research and Development, University of Copenhagen, Fredriksberg, Denmark. 'Laboratory of Entomology, National Institute of Health, PO Box 264, Maputo, Mozambique. ${ }^{3}$ MOZDAN (Mozambican-Danish Rural Malaria Project), PO Box 8, Morrumbene, Inhambane Province, Mozambique. ${ }^{4}$ Swiss Tropical and Public Health Institute, Socinstrasse 57, PO Box, CH-4002, Basel, Switzerland. ${ }^{5}$ University of Basel, PO Box, CH-4003, Basel, Switzerland.

Received: 9 April 2013 Accepted: 11 June 2013

Published: 17 June 2013

\section{References}

1. Tolstoy L: Anna Karenina. Moscow: The Russian Messenger; 1878.

2. Roubaud E: Les désharmonies de la fonction rénale et leurs conséquences biologiques chez les moustiques. Les faits et leurs applications. Ann Inst Pasteur 1923, 37:627-679.

3. Washino RK: The physiological ecology of gonotrophic dissociation and related phenomena in mosquitoes. J Med Entomol 1977, 13:381-388.

4. Rao W: On gonotrophic discordance among certain Indian Anopheles. Indian J Malar 1947, 1:43-50.

5. Strickland G: School of Tropical Medicine. In Annual report of the Calcutta School of Tropical Medicine and the Carmichael Hospital for Tropical Diseases 1937. Calcutta; 1938.

6. Büttiker W: Observations on the physiology of adult anophelines in Asia. Bull World Health Organ 1958, 19:1063-1071.

7. Omer SM, Cloudsley-Thompson JL: Survival of female Anopheles gambiae Giles through a 9-month dry season in Sudan. Bull World Health Organ 1970, 42:319-330.

8. Dukeen MYH, Omer SM: Ecology of the malaria vector Anopheles arabiensis Patton (Diptera: Culicidae) by the Nile in northern Sudan. Bull Entomol Res 1986, 76:451-467.

9. Charlwood JD, Qassim M, Elnsur El, Donnelly M, Petrarca V, Billingsley PF, Pinto J, Smith T: The impact of indoor residual spraying with malathion on malaria in refugee camps in eastern Sudan. Acta Trop 2001, 80:1-8.

10. Holstein MH: Biology of Anopheles gambiae: Research in French West Africa. Geneva: World Health Organization; 1954 [World Health Organization Monograph Series, vol. 9]. 
11. Coetzee M, Hunt RH, Wilkerson R, Della Torre A, Coulibaly MB, Besansky NJ: Anopheles coluzzii and Anopheles amharicus, new members of the Anopheles gambiae complex. Zootaxa 2013, 3619:246-274.

12. Lehmann T, Dao A, Yaro AS, Adamou A, Kassogue Y, Diallo M, Sékou T, Coscaron-Arias C: Aestivation of the African malaria mosquito, Anopheles gambiae in the Sahel. AmJTrop Med Hyg 2010, 83:601-606.

13. Adamou A, Dao A, Timbine S, Kassogué Y, Yaro AS, Diallo M, Traoré SF, Huestis DL, Lehmann T: The contribution of aestivating mosquitoes to the persistence of Anopheles gambiae in the Sahel. Malar J 2011, 10:151.

14. Muir DA: Anopheline mosquitoes: vector reproduction, life-cycle and biotope. In Malaria: principles and practice of malariology, Volume 1. 1st edition. Edited by Wernsdorfer WH, McGregor I, Edinburgh: Churchill Livingstone; 1988:431-452.

15. Gillies MT: The recognition of age-groups within populations of Anopheles gambiae by the pre-gravid rate and the sporozoite rate. Ann Trop Med Parasitol 1954, 48:58-74.

16. Gillies MT: The duration of the gonotrophic cycle in Anopheles gambiae and Anopheles funestus, with a note on the efficiency of hand catching. East Afr Med J 1953, 30:129-135.

17. Charlwood JD, Vij R, Billingsley PF: Dry season refugia of malariatransmitting mosquitoes in a dry savannah zone of east Africa. AmJTrop Med Hyg 2000, 62:726-732.

18. Leeson HS: Anopheline Mosquitos in Southern Rhodesia 1926-1928. A Report on Investigations Made During Researches on Blackwater Fever Conducted by Dr. G.R. Ross. London: The London School of Hygiene and Tropical Medicine; 1931 [Memoir Series of the London School of Hygiene and Tropical Medicine, vol. 4.]

19. Gillies MT, De Meillon B: The anophelinae of Africa south of the Sahara (Ethiopian Zoogeographical Region). 2nd edition. Johannesburg: South African Institute for Medical Research; 1968 [Publications of the South African Institute for Medical Research, vol. 54].

20. Giannini A, Biasutti M, Held I, Sobel A: A global perspective on African climate. Clim Change 2008, 90:359-383.

21. Charlwood JD: Studies on the bionomics of male Anopheles gambiae Giles and male Anopheles funestus Giles from southern Mozambique. J Vector Ecol 2011, 36:382-394.

22. Gillies MT, Coetzee M: Supplement to the anophelinae of Africa south of the Sahara (Ethiopian Zoogeographical Region). Johannesburg: South African Institute for Medical Research; 1987 [Publications of the South African Institute for Medical Research, vol. 55].

23. Wirtz RA, Zavala F, Charoenvit Y, Campbell GH, Burkot TR, Schneider I, Esser KM, Beaudoin RL, Andre RG: Comparative testing of monoclonal antibodies against Plasmodium falciparum sporozoites for ELISA development. Bull World Health Organ 1987, 65:39-45.

24. Products: Soil Moisture, Solar Radiation, Data Loggers, Canopy Analysis, Plant Science. [http://www.delta-t.co.uk/product-category.asp?div=Meteorology\% 20and\%20Solar]

25. R Core Team: R: A Language and Environment for Statistical Computing. Vienna: R Foundation for Statistical Computing; 2013.

26. Nedelman J: A negative binomial model for sampling mosquitoes in a malaria survey. Biometrics 1983, 39:1009-1020.

\section{Submit your next manuscript to BioMed Central and take full advantage of:}

- Convenient online submission

- Thorough peer review

- No space constraints or color figure charges

- Immediate publication on acceptance

- Inclusion in PubMed, CAS, Scopus and Google Scholar

- Research which is freely available for redistribution
C Biomed Central 